\title{
Labial salivary gland biopsy assessment in rheumatoid vasculitis
}

Rene-Marc Flipo, Anne Janin, Eric Hachulla, Eric Houvenagel, Armelle Foulet, Thierry Cardon, Anne Desbonnet, Bruno Grardel, Bernard Duquesnoy, Bernard Delcambre

\begin{abstract}
Objectives-To assess the vascular involvement in labial salivary gland (LSG) from patients with rheumatoid vasculitis (RV).

Methods-Forty seven patients with rheumatoid arthritis (RA) took part in a prospective study. Among them, 12 had proven RV. LSG biopsy was performed after local anaesthesia.

Results-Histological appearance of inflammatory vascular damage was observed in all but one patient with proven RV $(92 \%)$. Inflammatory vascular involvement was also identified in LSG biopsy of seven patients with RA $(20 \%)$ and only one patient in the control group $(8 \%)$. A second specimen of LSG was studied after a mean treatment period of six months and failed to show any feature of inflammatory vascular involvement in three of the five cases that were analysed. Conclusions-The study emphasises the high incidence of immunopathological features of microvascular damage in patients with RV. LSG biopsy is minimally invasive and may be a potential useful tool for the diagnosis of RV especially when skin lesions are absent or impossible to biopsy. The assessment of the predictive value of positive LSG biopsy in RA requires a long term prospective study.
\end{abstract}

(Ann Rheum Dis 1994; 53: 648-652)

Rheumatoid vasculitis (RV) is an uncommon but extremely severe complication of rheumatoid arthritis (RA). The wide spectrum of cutaneous and systemic manifestations of vasculitis can sometimes explain the difficulties of the diagnosis. Estimates of the clinical incidence of $\mathrm{RV}$ in patients with RA have ranged from $0.5-15 \% .{ }^{12}$ However, biopsy specimen of skin or muscle in patients with RA

Table 1 Demographic and laboratory data

\begin{tabular}{lclc}
\hline & $\begin{array}{l}\text { Rheumatoid vasculitis } \\
\text { (group } I) N=12\end{array}$ & $\begin{array}{l}\text { Rheumatoid arthritis } \\
\text { (group II) } N=35\end{array}$ & $p$ Value \\
\hline Sex ratio (F/M) & $6 / 6$ & $20 / 15$ & NS \\
Mean age (years) & $60(8)$ & $55(13)$ & NS \\
Mean duration of the disease (years) & $10($ range 1-18) & 11 (range 1-42) & NS \\
Erosive disease & 12 & 33 & NS \\
Positive RF (IgM) & $10(80 \%)$ & $21(60 \%)$ & NS \\
Circulating immune complexes & $8(60 \%)(4 \cdot 48)$ & $19(55 \%)(4 \cdot 16)$ & NS \\
$\quad$ (median value) N $<1,5$ mg/l] & 215 & 220 & NS \\
von Willebrand Ag (median value) & & & \\
$\quad$ [N: 0-150\%] & & & \\
\hline RF: Rheumatoid Factor. & & &
\end{tabular}

Correspondence to: Service de Rhumatologie, Hopital B,

(Pr B Delcambre)

Universitaire

59037 Lille, France

Accepted for publication

25 May 1994

Department of
Rheumatology,
Hopital B, Lille,
France
R-M Flipo
T Cardon
A Desbonnet
B Duquesnoy
B Delcambre
Department of
Pathology,
Hopital Calmette,
Lille, France
A Janin
A Foulet
Department of
Internal Medicine,
Hopital Huriez,
Lille, France
E Hachulla
Department of
Rheumatology,
Hopital St-Philibert,
Lomme-Les-Lilles,
France
E Houvenagel
Department of
Rheumatology,
Institut Calot,
Berck/Mer, France
B Grardel
Correspondence to:
Dr Rene-Marc Flipo,
Service de Rhumatologie,
Hopital B,
(Pr B Delcambre),
Centre Hospitalier et
Universitaire,
59037 Lille, France
Accepted for publication
25 May 1994

have found peri-vascular infiltration with inflammatory cells and immunoglobulins or complement deposits in $10-50 \%$ of the patients, suggesting that subclinical systemic vasculitis in often present. ${ }^{34}$ Conn $e t ~ a l^{4}$ have also suggested that the site chosen for biopsy probably has an important role in determining the frequency of positive results. Moreover, although the presence of vasculitis in rectal biopsy seems to be very specific and associated with a worse prognosis in RV, the sensitivity of this method is only $0 \cdot 34 .^{5}$

Whilst obtaining LSG biopsy to assess Sjögren's syndrome or exclude amyloidosis in patients with connective tissue diseases, we noted the presence of immunopathological features of microvascular damage suggesting vasculitis in some of the biopsies. ${ }^{6}$ For this reason, the aim of this study was to identify possible LSG involvement in patients with RV, and to investigate the use of LSG biopsy in the diagnosis of RV. We compared the results of LSG biopsy obtained in 12 patients with proven RV with those obtained in 35 patients with RA and a control group of 13 patients without evidence of inflammatory disease.

\section{Patients and methods}

Our study comprised 47 patients fulfilling the criteria of the American rheumatism association for RA to assess LSG involvement in $\mathrm{RV}$. According to disease status, we determined two groups:

Group I were 12 patients with proven evidence of RV who fulfilled the diagnostic criteria proposed by Scott and Bacon. ${ }^{7}$ The diagnosis of RV depended on the presence of one or more of: (1) mononeuritis multiplex; (2) peripheral gangrene; (3) biopsy evidence of acute necrotising arteritis plus systemic illness; (4) deep cutaneous ulcers in the absence of significant artherosclerosis or active extraarticular disease if associated with typical digital infarcts or biopsy evidence of vasculitis. The details of these 12 patients with RV are given in tables 1 and 2. Patients who had only peri-ungueal infarctions were not included.

Group II were 35 consecutive patients with RA who had no clinical or histological evidence of vasculitis. In most cases these patients were admitted to hospital for progressive disease requiring a pulse of methylprednisolone and a new second-line drug. None had Felty's syndrome.

Control group were 13 age-related patients suffering from chronic low back pain or sciatica 
Table 2 Group I: clinical data

\begin{tabular}{|c|c|c|c|c|c|c|}
\hline Patient & $\begin{array}{l}\text { Systemic } \\
\text { illness }\end{array}$ & Cutaneous signs & Neurological signs & Other symptoms & Second line drug & $\begin{array}{l}\text { Cortico } \\
\text { steroids }\end{array}$ \\
\hline 1 & + & Purpura, non healing leg ulcers & Peripheral neuropathy & Sicca syndrome & Parenteral gold & + \\
\hline 2 & + & Palpable purpura & Mononeuritis multiplex & - & & + \\
\hline 3 & + & $\begin{array}{l}\text { Livedo reticularis, Purpura, } \\
\text { non healing leg ulcers }\end{array}$ & Mononeuritis multiplex & - & Parenteral gold & + \\
\hline 4 & + & Purpura, non healing leg ulcers & Peripheral neuropathy & - & Methotrexate & + \\
\hline 5 & - & Extensive leg ulcers & Mononeuritis multiplex & Myocardial infarction & Methotrexate & + \\
\hline 6 & + & Livedo reticularis, gangrene & Mononeuritis multiplex & - & Methotrexate & - \\
\hline 7 & + & Purpura, erythrocyanosis & Peripheral neuropathy & Raynaud's phenomenon & Tiopronine & - \\
\hline 8 & + & $\begin{array}{l}\text { Livedo reticularis, non healing } \\
\text { leg ulcers }\end{array}$ & Mononeuritis multiplex & - & - & + \\
\hline 9 & + & Livedo reticularis & Peripheral neuropathy & Sicca syndrome & Parenteral gold & + \\
\hline 10 & + & Purpura, gangrene & Mononeuritis multiplex & - & - & + \\
\hline 11 & + & - & Mononeuritis multiplex & - & - & + \\
\hline 12 & + & Non healing leg ulcers & Mononeuritis multiplex & Bowel infarction & Methotrexate & + \\
\hline
\end{tabular}

and were included in the control group after their informed consent was obtained.

Physical examination was carried out on each patient by two investigators. Active polyarthritis was considered if the three following criteria were present: nocturnal painful awakening, more than one hour of morning stiffness, at least three arthritic joints.

Besides routine laboratory work, the evaluation included the level of circulating immune complexes (immunolaser nephelometric analysis). von Willebrand factor antigen concentration in sera was measured by enzyme linked immunosorbent assay using commercial antisera (Kit Asseracrom, VWF, Diagnostica, Stago). Results were expressed as a percentage of a normal control (healthy blood donors). The normal range was: $0-150 \%$.

\section{PATHOLOGICAL STUDY}

All patients had LSG biopsy under local anaesthesia ( $1 \%$ xylocaine hydrochloride with $1 / 8000$ adrenaline) with their informed consent. Three minor salivary glands were excised from the lower labial mucosa for each patient. Incisions were minimal, selectively performed over the salivary duct apertures in the mouth and no suture was required.

The salivary glands were immediately cut into two. One half was immediately snapfrozen in liquid nitrogen, the other half was fixed in $4 \%$ paraformaldehyde in cacodylate buffer and further processed for parafin embedding. Serial sections were made from the parafin blocks. Haematoxylin-eosin and MayGrunwal-Giemsa stains were systematically performed on every other section. On cryocut sections, antibodies directed against IgA, IgG, IgM, kappa and lambda light chains, and $\mathrm{C} 3$ (Behring Laboratories) were used with a direct immunofluorescent method.

The slides were analysed by two different pathologists and reviewed a third time in a masked fashion. On parafin sections, the analysis focussed on the evaluation of the infiltrate according to Chisholm's focus score (a focus is an aggregate of more than 50 round cells on four square millimetres). The assessment of immunopathological features of vascular damage was based on the examination of: (1) damage of blood vessels by fibrin deposition; (2) presence of infiltrate of leukocytoclastic polymorphonuclear leukocytes, or lymphocytes, or eosinophils; (3) presence of inflammatory granuloma and (4), on cryocut sections, the analysis was focussed on the presence of immune deposits on the vessel walls.

After a mean period of nine months after the onset of the treatment based on pulse of intravenous cyclophosphamide plus methylprednisolone given by intermittent bolus intravenous injection, ${ }^{7}$ five patients of group I with RV had a second LSG biopsy performed.

Statistical analysis was performed by the research department of medical statistics (CERIM). Non parametric $t$ tests were used as well as Wilcoxon's and Fisher's procedures.

\section{Results}

There was no significant difference in demographic and clinical data between the two groups of patients with RA (table I). However, most of the patients with RV (group I) had mild joint activity compared with the severe joint disease observed in group II patients who were admitted to hospital for evolutive RA. At the time of the study, there was no statistical difference in the treatment of RA (antiinflammatory drugs, corticosteroids, second line drugs). Four patients from group I and eight from group II were receiving methotrexate with a mean dose of $7.5 \mathrm{mg} /$ week $(\mathrm{p}>0.05)$.

No significant difference was observed between the two groups of patients with RA for all laboratory tests: erythrocyte sedimentation rate, C-reactive protein, fibrinogen, IgM rheumatoid factor, $\mathrm{CH} 50, \mathrm{C} 3, \mathrm{C} 4$. Mean value of IgM rheumatoid factor (laser nephelometric analysis, normal value $<40 \mathrm{UI} / \mathrm{ml}$ ) was no different between the two groups due to one very high value in one of the patients from group II $(7000 \mathrm{UI} / \mathrm{ml})$. Mean value and median of serum levels of immune complexes were higher in patients from group I but the difference was not statistically significant. von Willebrand factor antigen concentration in serum was not statistically elevated in patients with RV compared with patients of group II. However, von Willebrand factor antigen was strongly correlated with ESR, CRP, fibrinogen, rheumatoid factor and serum concentration of immunes complexes $(p<0.01)$.

In 11 of the 12 patients $(92 \%)$ with proven RV (group I), immunopathological features of micro-vascular damage (size of the vessels involved $=50-80 \mu$ for capillaries, $100-200 \mu$ 
Table 3 Immunopathological results

\begin{tabular}{llll}
\hline & $\begin{array}{l}\text { Group I } \\
\text { Rheumatoid } \\
\text { vasculitis } \\
N=12\end{array}$ & $\begin{array}{l}\text { Group II } \\
\text { Rheumatoid } \\
\text { arthritis } \\
N=35\end{array}$ & $\begin{array}{l}\text { Control } \\
\text { group }\end{array}$ \\
& 11 & 12 & 13 \\
\hline $\begin{array}{l}\text { Vascular wall oedema } \\
\begin{array}{l}\text { Damage of blood vessels } \\
\text { by fibrin deposition }\end{array}\end{array}$ & 9 & 6 & 1 \\
$\begin{array}{l}\text { Leukocytoclastic } \\
\text { polymorphonuclear } \\
\text { leukocytes }\end{array}$ & 5 & 2 & 0 \\
$\begin{array}{l}\text { Eosinophilic infiltrate } \\
\text { Lymphocytic infiltrate }\end{array}$ & 2 & & \\
- Focus score >1 & 3 & 1 & 0 \\
- Focus score < 1 & 6 & 5 & 0 \\
$\begin{array}{l}\text { Positive IF } \\
\text { - IgM }\end{array}$ & 9 & 7 & 1 \\
- IgG & 3 & 3 & 0 \\
- IgA & 0 & 0 & 0 \\
- C3 & 12 & 0 & 0 \\
\hline
\end{tabular}

Table 4 Group II: clinical data of the patients with positive biopsy

\begin{tabular}{lllllll}
\hline Patient & $\begin{array}{l}\text { Systemic } \\
\text { illness }\end{array}$ & Cutaneous signs & Neurological signs & $\begin{array}{l}\text { Other } \\
\text { symptoms }\end{array}$ & Second line drug & $\begin{array}{l}\text { Cortico } \\
\text { steroids }\end{array}$ \\
\hline 1 & - & - & Peripheral neuropathy & - & Sulfasalazine & + \\
2 & - & $\begin{array}{c}\text { Non palpable } \\
\text { purpura }\end{array}$ & - & - & Methotrexate & - \\
3 & - & - & - & - & Parenteral gold & + \\
4 & - & Leg ulcer & - & - & - & + \\
5 & - & - & - & - & Methotrexate & + \\
6 & - & - & Peripheral neuropathy & - & - & + \\
7 & - & Leg ulcer & - & - & Sulfasalazine & + \\
\hline
\end{tabular}

${ }^{\star}$ For these two patients, cutaneous biopsies showed any feature of vasculitis.

for veinules) were seen on the LSG biopsy. Table 3 shows the pathological features observed on LSG biopsy. Similar pathological features were only found in seven patients from group II $(p<0.01)(20 \%)$ and in only one patient of the control group $(p<0.01)(8 \%)$. The details of these seven patients of group II with inflammatory vascular damage on LSG biopsy are given in table 4 . The focal distribution of inflammatory vascular damage is illustrated in the figure. This focal involvement requires the systematic examination of serial paraffin section. The incidence of all the pathological features is significantly higher in group I compared with group II (except for the presence of eosinophilic infiltrate and anti-IgG and anti-IgA positive immunofluorescence), $(\mathrm{p}<0.01)$ and the control group $(\mathrm{p}<0.003)$. We failed to see any evidence of necrotising vasculitis and this may be due to the absence of muscular arteries on LSG biopsy (absence of fatty tissue). The control patient with histological inflammatory vascular involvement was a women aged 45 admitted to hospital for chronic low back pain and receiving paracetamol.

A focus score $>1$ was present in three patients in group I, five patients from group II and none of the controls $(p>0.05)$.

With a mean follow up of 18 months, only one of the patients with clinical evidence of vasculitis died (patient deceased of unknown origin). Five patients of group I were reassessed after a mean duration of treatment of nine months. A full clinical recovery had been observed in all these cases when a second LSG biopsy was performed. Pathological features of inflammatory vascular damage were present in two cases but, they were not found in the three other cases.

\section{Discussion}

To our knowledge, the present study is the first report which stresses the usefulness of LSG biopsy in diagnosing inflammatory microvascular damage in patients with RV.

Most clinical and laboratory results agree with data previously reported with the exception in a lower incidence of rheumatoid nodules in patients with RV. ${ }^{2}$ It is currently acknowledged that most patients with RV have mild joint activity. ${ }^{1-3}$ Only four patients were

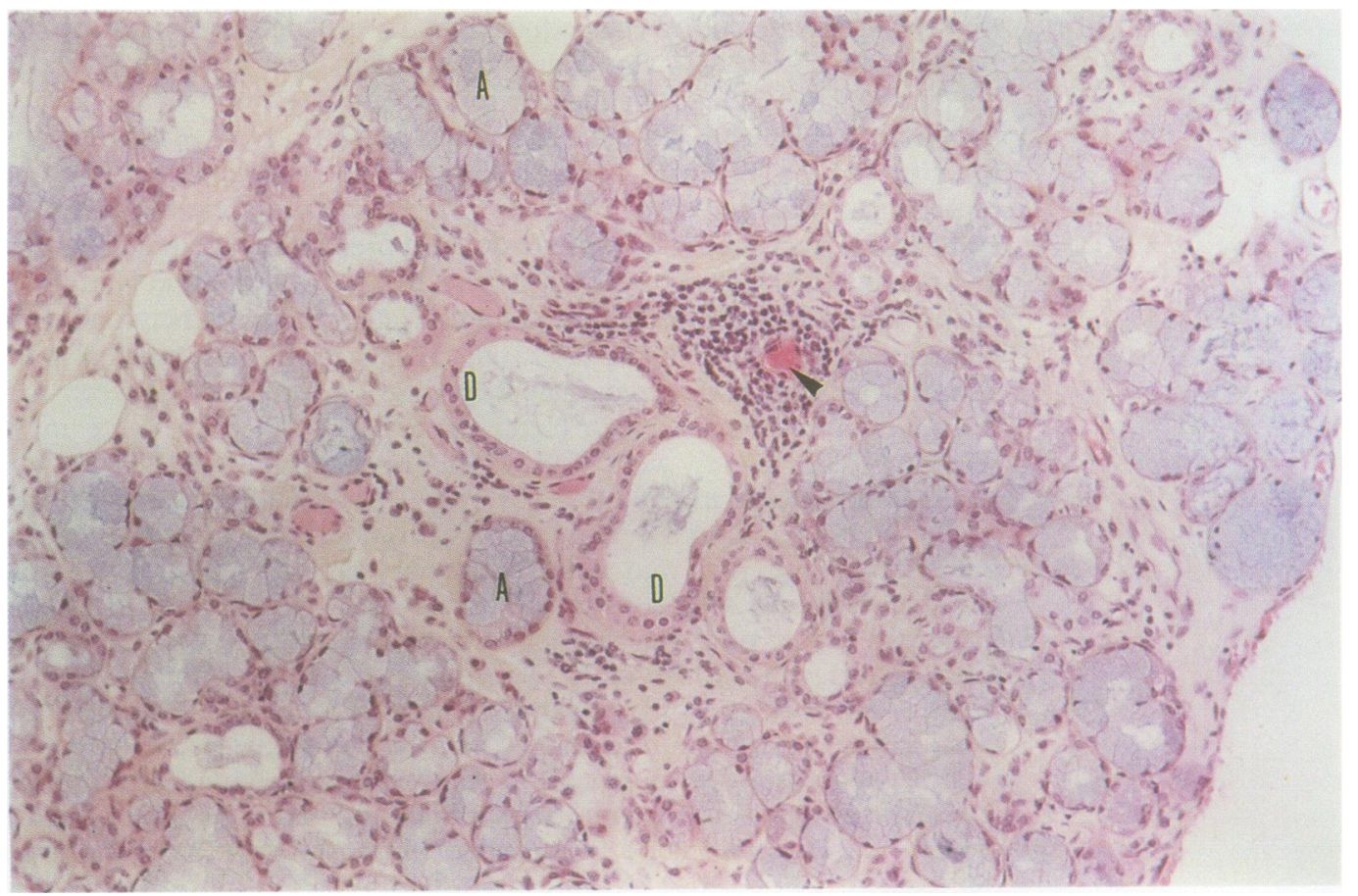


taking methotrexate when they developed vasculitis. In the present study, levels of von Willebrand factor antigen was not significantly elevated in patients with RV, in contrast to previous studies on vasculitis associated with other diseases. ${ }^{9}$ Nevertheless, Blann et $a l^{10}$ failed to find any significant difference between patients with RV and those with RA. von Willebrand factor antigen might be considerably elevated only in systemic necrotising and large vessels arteritis. ${ }^{9}$

$\mathrm{RV}$ is commonly described as a panarteritis that involves blood vessels of all sizes, particularly small arteries such as the digital arteries. ${ }^{2} \mathrm{RV}$ may affect all layers of the vessel wall, especially the adventitia, with infiltration with mononuclear cells. Only some patients have involvement of medium and large rather than small arteries (necrosis fibrinoid change, disruption of the internal elastic lamina), pathological alterations resembling those of polyarteritis nodosa.

A variety of tissues have been biopsied to look for pathological evidence of vasculitis in patients with RA. Biopsy specimens of muscle in patients with RA have revealed perivascular infiltration with inflammatory cells in $10 \%$ of the patients. ${ }^{4}$ Sural nerve biopsy is sometimes used but both sural nerve and muscle biopsies are surgical procedures causing discomfort and morbidity sequellae and may be dangerous in patients with widespread cutaneous lesions.

Thirty per cent of patients with RA had an infiltrate of mononuclear cells around the dermal blood vessels in normal skin, correlated with disease activity and extra-articular manifestations of sero-positive RA. ${ }^{11}$ However, the presence of immune deposits (IgM, C3) is frequent in normal appearing skin vessels in $\mathrm{RA},{ }^{12}$ and does not differentiate between seropositive rheumatoid patients who have clinical vasculitis from those who do not have clinical vasculitis. $^{5}$

Bernelot Moens et al ${ }^{13}$ suggest that perivascular infiltration in normal skin of patients with RA is merely an epiphenomenom of the deposition of rheumatoid factor and was not prognostic for the clinical syndrome of rheumatoid vasculitis.

Vasculitis was first described on rectal biopsy in 1968 by Schneider and Dobbins ${ }^{14}$ in five of 22 patients with RA. It was a non necrotising arteritis in four cases and none of the five patients had clinical evidence of systemic vasculitis. Tribe et $a l^{6}$ investigated the rectal biopsy in RV. When diagnosing vasculitis in this study rectal biopsy appeared very specific (only one positive biopsy in a control serie of 46 RA) but not sensitive (only 34\%). Moreover, a positive rectal biopsy for vasculitis was associated with a poor prognosis. This procedure appeared to be not as safe as LSG biopsy, two cases of intestinal perforation being mentioned in this series. ${ }^{6}$

LSG biopsy is easy to perform and appears to be a relatively minor and safe procedure. None of our patients had pain, wound breakdown, or infection. There were no complaints of scarring of the area. Some authors consider LSG biopsy as a potentially traumatic procedure due to possible damage to branches of the mental nerve. However, these investigators excise six to eight of the minor salivary glands and close the wound with one or two black silk sutures. ${ }^{15}$

Subclinical vasculitis is probably a more common and more widespread disease than is clinically apparent. In the present study, LSG biopsy was positive in $20 \%$ of patients with RA and no evidence of vasculitis according to Scott and Bacon criteria. ${ }^{7}$ However, we cannot exclude such a diagnosis particularly in the two patients with symetrical peripheral neuropathy but no neuromuscular biopsy. LSG inflammatory vascular damage may reflect a systemic involvement of small size vessels which rarely causes serious internal organ dysfunction. The size of vessels involved and the absence of necrotising arteritis in LSG biopsy do not favour a worse prognostic significance. The absence of muscular arteries on LSG tissue and the early detection of microvascular damage on LSG biopsy might explain in our study the absence of necrotising arteritis (late stage of vasculitis). With a mean follow up of two years after diagnosis of RV, no recurrence was observed in patients from group I. With a same follow up of two years, no case of RV occurred in the seven patients (group II) with RA and positive LSG biopsy.

In conclusion, biopsy of LSG of the lower lip has now been used for many years, particularly in diagnosing sarcoidosis or amyloidosis and in the assessment of criteria for Sjögren's syndrome. The present study demonstrates that LSG biopsy seems to be a highly sensitive method for the diagnosis of immunopathological microvascular involvement and might suggest the diffusion of the vascular inflammatory process in RV. LSG biopsy can be done when vasculitis is suspected, particularly in the absence of skin lesion. However, the prognostic value of LSG involvement in RV remains unknown. Longitudinal studies in RA may give more information about the clinical and immunological relevance of the presence of vasculitis in LSG.

We thank Mrs F Gaoua who contributed to the typing of this manuscript and Dr R Lafyatis for helpful discussion and for reviewing the manuscript.

We also thank Mrs Dehier for technical assistance in We also thank Mrs Dehier for technical assistance in
performing the statistical analysis and Professor J Goudemand for the von Willebrand factor antigen dose.

1 Scott D G, Bacon P A, Tribe C R. Systemic rheumatoid vasculitis: A clinical and laboratory study of 50 cases. Medicine 1981; 60: 288-97.

2 Vollertsen R S, Conn D L, Ballard D J, Ilstrup D M, Kazmar R E, Silverfield J C. Rheumatoid vasculitis: survival and associated risk factors. Medicine 1986; 65: survival

3 Sokoloff L, Wilens S L, Bunim J J. Arteritis of striated muscle in theumatoid arthritis. Am F Pathol 1951; 27: 157-73.

4 Conn D L, Schroeter A L, McDuffie F C. Cutaneous vessel immune deposits in rheumatoid arthritis. Arthritis Rheum 1976; 19: 15-20.

5 Tribe C R, Scott D G I, Bacon P A. Rectal biopsy in the diagnosis of systemic vasculitis. $\mathcal{f}$ Clin Pathol 1981; 34: 843-50.

6 Janin A. Aspect histologique des glandes salivaires accessoires dans le lupus érythémateux. Ann Med Interne $1990 ; 141: 247-49$.

7 Scott D G, Bacon P A. Intravenous cyclophosphamide plus methylprednisolone in treatment of systemic rheumatoid vasculitis. Am $\mathcal{F}$ Med 1984; 76: 377-84.

8 Lie J T. Illustrated histopathologic classification criteria for selected vasculitis syndromes. Arthritis Rheum 1990; 33: 1074-87. 
9 Woolf A D, Wakerley G, Wallington T B, Scott D G I, Dieppe PA. Factor VIII related antigen in the assessment Dieppe P A. Factor VIII related antigen in the
of vasculitis. Ann Rheum Dis 1987; 46: 441-7.

10 Blann A D, Wainwright A C, Sheeran T P, Emery P. Venostasis, subclinical vasculitis and von Willebrand factor antigen. $\mathrm{Br} \mathcal{F}$ Rheumatol $1991 ; 30$ : 373-5.

11 Westedt M L, Meijer C J L M, Vermeer B J, Cats A, Vries de E. Rheumatoid arthritis. The clinical significance of histo-and immunopathological abnormalities in normal skin. F Rheumatol 1984; 11: 448-53.

12 McGill P E, Brougham P A, Tulloch J. Immune deposits in the skin of patients rheumatoid arthritis. $\mathcal{F}$ Rheumatol $1984 ; 11: 454-6$
13 Bernelot Moens H J, Ament $\mathrm{H}$ J W, Vroom Th M, Feltkamp T E W, Van der Korst J K. Perivascular infiltration in normal skin of patients with rheumatoid arthritis: association with rheumatoid factors and

14 Schneider R E, Dobbins W O. Suction biopsy of the rectal mucosa for diagnosis of arteritis in rheumatoid arthritis and related diseases. Ann Intern Med 1968; 68: 561-8.

15 Richards A, Mutlu S, Scully C, Maddison P. Complications associated with labial salivary gland biopsy in the investigation of connective tissue disorders. Ann Rheum Dis 1992; 51: 996-7. 